\title{
Italia Ti Ascolto [Italy, I am listening]: an app-based group psychological intervention during the COVID-19 pandemic
}

\author{
Laura Antonia Lucia Parolin,,${ }^{1,2}$ Ilaria Maria Antonietta Benzi, ${ }^{3}$ Erika Fanti, ${ }^{1}$ Alberto Milesi, ${ }^{1}$ Pietro Cipresso, ${ }^{3,4}$ \\ Emanuele Preti ${ }^{1,2}$
}

${ }^{1}$ University of Milano-Bicocca, Milan; ${ }^{2}$ Bicocca Center for Applied Psychology, Milan; ${ }^{3}$ IRCCS Istituto Auxologico Italiano, Milan; ${ }^{4}$ Catholic University of the Sacred Heart, Milan, Italy

\begin{abstract}
The onset of the coronavirus disease 2019 (COVID-19) pandemic impacted individuals' psychological wellbeing resulting in heightened perceived stress, anxiety, and depression. However, a significant issue in accessing psychological care during a lockdown is the lack of access to in-person interventions. In this regard, research has shown the efficacy and utility of psychological app-based interventions. 'Italia Ti Ascolto' (ITA) has been developed as a population tailored internet-based intervention to offer an online professional solution for psychological support needs. The ITA app is available on iOS and Android systems. Users completed a baseline assessment on emotion regulation strategies (cognitive reappraisal and expressive suppression), psychological stress, anxiety, depression, and perceived social support. Participants could select among several one-hour long clinical groups held by expert psychotherapists. After every session, people were asked to complete a quick users' satisfaction survey. Our contribution presents ITA's intervention protocol and discusses preliminary data on psychological variables collected at baseline. Data showed significant associations between emotion regulation strategies, symptoms of depression and anxiety, and level of stress. Moreover, the role of perceived social support is considered. Future developments and implications for clinical practice and treatment are discussed.
\end{abstract}

Key words: COVID-19; E-mental health; online psychological interventions; groups.

\section{Introduction}

Extraordinary events such as a global pandemic have a significant impact on individuals' psychological wellbeing, fostering negative consequences for the community and influencing economics, politics, and culture.

Correspondence: Emanuele Preti, University of Milano-Bicocca, Piazza dell'Ateneo Nuovo 1, 20126 Milano, Italy.

E-mail: emanuele.preti@unimib.it

Citation: Parolin, L.A.L., Benzi, I.M.A., Fanti, E., Milesi, A., Cipresso, P., \& Preti, E. (2021). Italia Ti Ascolto [Italy, I am listening]: an app-based group psychological intervention during the COVID-19 pandemic. Research in Psychotherapy: Psychopathology, Process and Outcome, 24(1), 42-52. doi: 10.4081/ripppo. 2021.517

Received for publication: 10 January 2021

Revision received: 18 February 2021.

Accepted for publication: 20 February 2021.

This work is licensed under a Creative Commons Attribution NonCommercial 4.0 License (CC BY-NC 4.0).

${ }^{\circ}$ Copyright: the Author(s), 2021

Licensee PAGEPress, Italy

Research in Psychotherapy:

Psychopathology, Process and Outcome 2021; 24:42-52

doi:10.4081/ripppo.2021.517
Indeed, the experience of isolation, fear of infection, boredom, and overall uncertainty has a significant toll on individuals' mental health (Brooks et al., 2020) fostering symptoms of anxiety, depression and overall perceived psychological distress (Wang et al., 2020a). A recent study (Taquet, Luciano, Geddes, \& Harrison, 2020) highlighted a bidirectional relationship between mental health and coronavirus disease 2019 (COVID19) infection: having COVID-19 increases the risk of developing psychiatric disorders while having a psychiatric disorder would increase the chances of getting infected. Consistently, some authors (Preti, Di Pierro, Fanti, Madeddu, \& Calati, 2020) have recently pointed out that patients with personality disorders, such as borderline personality disorder (Benzi, Di Pierro, De Carli, Cristea, \& Cipresso, 2020), might be particularly affected by pandemic distress, experiencing an exacerbation of symptoms. Thus, it is crucial to assess the level of psychological distress of all affected populations: people that contracted the virus, their caregivers and relatives, healthcare workers, as well as adolescents and children (Mazza et al., 2020; Petzold et al., 2020; Preti et al., 2020; Qiu et al., 2020).

Considering the Italian population, the COVID-19 outburst had a massive impact (number of cases and deaths), especially on the Lombardy region, where the first significant European outbreak was recorded requiring the activation of new widely and broadly accessible welfare resources to respond to citizens' distress (Percudani, 
Corradin, Moreno, Indelicato, \& Vita, 2020; Rapisarda et al., 2020).

Chevallard and colleagues (2020) found that during the first phase of the Italian lockdown, Intensive Care Unit (ICU) accesses due to suicidal attempts were three times higher than in previous months. Tan and colleagues (2020) also found that healthcare workers showed higher levels of perceived stress, depressive symptoms, and anxiety levels during the pandemic, and, more importantly, struggled to ask for psychological support. However, Romero and colleagues (2020) found that healthcare workers who received psychotherapy treatment showed diminished stress levels. These results underline the importance of assessing individuals' psychological wellbeing in the general population and at-risk groups, advocating the significant role of psychological support during dramatic times like a pandemic outbreak.

However, a crucial issue in accessing psychological care during a lockdown is the lack of access to in-person interventions (Kang et al., 2020). In the last decade, researchers implemented several interventions to help overcome those difficulties, integrating new technologies with interventions such as online individual psychological consulting via videoconferencing and chat-groups (Richardson et al., 2009; Chakrabarti, 2015; da Silva, Siegmund, $\&$ Bredemeier, 2015). Moreover, long-distance support through videoconferencing and chats is also used in group interventions (Marziali et al., 2006; Banbury, Nancarrow, Dart, Gray, \& Parkinson, 2018).

Moreover, several recent contributions (Duan \& Zhu, 2020; Liu et al., 2020; Soklaridis et al., 2020; Zhang \& Smith, 2020; Zhang, Wu, Zhao, \& Zhang, 2020) suggest the utility and the efficacy of internet-based intervention groups to support people experiencing psychological distress due to the COVID-19 pandemic. We can gather precious information from several systematic reviews that investigated the effectiveness of internet-based interventions in general and related to the COVID-19 pandemic: indeed, according to Miralles and colleagues (2020), studies on app-based psychological interventions have remarkably increased between 2013 and 2018. Amidst them, depressive and anxiety disorders were the most studied.

More specifically, considering online interventions for depressive features, a systematic review by Burger, Neerincx, and Brinkman (2020) highlighted that $76 \%$ of the digital interventions are delivered via Web, and $85 \%$ of the studies investigated the efficacy of internet-based cognitive behavioral therapy (iCBT) highlighting successful treatments on depressive symptoms' reduction (e.g. Forsell et al., 2017; Hallgren et al., 2015; Schure et al., 2020; Miller et al., 2021). For example, Bakker and colleagues (2018) conducted a randomized controlled trial on three mental health apps efficacy: MoodPrism, MoodKit and MoodMission. Each app was based on cognitive-behavioral treatment model, and they were designed to improve emotional selfawareness, coping self-efficacy and mental health literacy in order to reduce depressive and anxiety symptomatology. Specifically, MoodPrism permits individuals to self-monitor their mood with daily surveys on emotional states in order to increase self-emotional awareness. Also, MoodKit provided four tools (a collection of activities, a thought checker, a mood tracker, and a journal) to individuals in order to improve their coping self-efficacy. MoodMission instead provided participants real CBT strategies when the individual self-reported depressive or anxious moods. Eventually, the apps resulted effective in reducing depressive symptoms but not anxious ones.

Other studies found significant reductions of depressive symptoms also through the delivery of mindfulness-based online interventions (Questret, Cropley, \& Fife-Schaw, 2018; Gili et al., 2020; Shankaland et al., 2020). Again, considering anxiety features, several studies demonstrated the efficacy of web- and app-based psychological interventions on anxiety reduction (e.g., Questret, Cropley, \& FifeSchaw, 2018; Rasanen et al., 2016; Lopez et al., 2019; Nissen et al., 2019; Kladnitski et al., 2020). Though Lindegaard and colleagues (2020) found no evidence of the difference between iCBT and internet-delivered psychodynamic psychotherapy (iPDT) in treating social anxiety disorder, most studies have focused primarily on cognitive-behavioral interventions and mindfulness-based interventions for the treatment of anxiety symptomatology.

Overall, in the adult population, research shows a significant efficacy of both self-help iCBT and guided iCBT in anxiety reduction in individuals diagnosed with a social anxiety disorder (Wang et al., 2020b) and of mindfulnessbased online interventions (Questret, Cropley, \& FifeSchaw, 2018; Segal et al., 2020). Finally, Lindegaard and colleagues (2020) investigated the differences in online interventions' efficacy based on cognitive-behavioral and psychodynamic approaches (Lis, Parolin, Calvo, Zennaro, Meyer, 2007; Benzi, Milesi, \& Parolin, 2021); researchers found no differences regarding their effectiveness, but both treatments significantly reduced anxiety symptoms.

In 2020, because of the COVID-19 pandemic outbreak, some authors investigated the use of online psychological interventions to reduce anxious and depressive symptomatology. For example, Zhang and Smith (2020) conducted a scoping review concerning digital tools developed specifically for COVID-19: only one specific study was found with these characteristics (Agyapong, 2020). However, later in the same year, more web- and app-based interventions were developed to overcome anxious and depressive symptomatology. For example, Zhou and colleagues (2020) found a significant effect of their WeChat intervention for suspected quarantined COVID19 patients in anxiety and depression reduction. Others have investigated the role of cognitive-behavioral therapy interventions delivered through digital tools and found promising results (Cheng, Casement, Kalmbach, Castelan, \& Drake, 2020; Wahlund et al., 2020). Also, studies concerning new technologies to deliver mindfulness- 
based intervention for people during the COVID-19 pandemic showed a significant reduction of depression and anxiety (Kubo et al., 2020; Matiz et al., 2020; Pizzoli et al., 2020; Ritvo et al., 2020). Moreover, both in the nonclinical population (Agyapong, 2020) and in the psychiatric population (Ben-Zeev, Buck, Meller, Hudenko, \& Hallgren, 2020), text message interventions have demonstrated their efficacy in reducing depression and anxiety.

All in all, taking advantage of online psychological interventions can be useful to overcome the adverse psychological effects of the COVID-19 pandemic facilitating a psychological intervention when the in-person option is not available, thus providing a tailored and population targeted treatment.

In this contribution we aim to describe 'Italia Ti Ascolto' (ITA), an app-based group psychological intervention supporting individuals experiencing psychological distress during the 2020 pandemic in the Lombardy region in Italy. Moreover, we aim to provide preliminary data on the ITA app, mainly on psychological variables assessed at baseline such as emotion regulation strategies, depressive and anxious symptoms, level of stress and perceived social support. Future developments and implications for clinical practice and treatment are discussed.

\section{Development of the 'Italia Ti Ascolto' app}

Given these premises, we developed 'Italia Ti Ascolto' (ITA), an app aimed at supporting individuals experiencing psychological distress during the 2020 pandemic in the Lombardy region in Italy. ITA is a smartphone app that has the following three objectives: to promptly and effectively contain emotional distress, to reduce pandemic preoccupation, and to link affected individuals to local and national mental health services. The Fondazione di Comunità Milano foundation (https://www.fondazionecomunitamilano.org) funded the ITA project, and the BiCApp research center (University of Milan-Bicocca) and the Order of Psychologists of Lombardy (OPL) developed the ITA app working with the IT company iMoobyte (https://imoobyte.com/).

The APP provides different online rooms, themed according to a specific target population and guided by a licensed group psychotherapist: room themes were defined in light of the experience of the most recent research on the needs of specific populations. Once the user downloaded the app and registered a profile, he/she had the opportunity to enroll in the groups, choosing from several time slots, thematic rooms, and professional therapists. At the time of registration to the specific virtual room, participants were asked to sign a privacy form, informed consent, and certify their legal age. The day before and on the day of the session, users received reminders to promote participation further.

Each meeting followed a definite process: first, a selfpresentation of the participants and a brief introduction of ITA. The therapists clarified the group's aims, specified privacy rules, and explained how the platform worked. Then, therapists started with the intervention phase, asking the participants to share their emotions and thoughts on their current situations. The meeting systematically ended with the presentation of the available mental health service in Lombardy.

The online group intervention was delivered for three months, from September 2020 to the end of November 2020 , and consisted of 16 up to 20 rooms per week. Each room lasted one hour, hosted up to 16 participants, and was led by an experienced psychotherapist.

We organized a weekly supervision meeting to monitor the service's status, discuss relevant clinical issues, share good communal practice, and share a clinical model for the intervention as well as providing scientific supervision. Also, meetings provided useful information to identify the app's strengths and weaknesses and implement changes in progress. For instance, new targets have been identified from time to time, including pregnant women and COVID-19 positive individuals. In contrast, some rooms have been modified to meet participants' needs (i.e., parents' group). To tackle participation issues, we implemented reminders, notifications on groups' status, and the possibility for psychotherapists to independently open and close the rooms.

\section{Themed rooms}

First, we included a room for those who experienced grief due to COVID-19. Indeed, the COVID-19 pandemic prevented individuals from experiencing the normal mourning process (for a review Stroebe, \& Schut, 2020) due to the mitigation measures involving physical distancing, lack of social support, a limited number of people allowed to attend the funeral, postponed or remote burials, hygiene norms, and measures. The efficacy of web-based treatment for grief has already been established (for a review, see Wagner, Rosenberg, Hofmann, \& Maass, 2020).

Second, parents represent another significant target as parents' job context (i.e., remote working and smart working) and emerging uncertainty led to creating a new narrative of family life and roles (De Carli, Tagini, Sarracino, Santona, \& Parolin, 2016; Cluver et al., 2020).

Third, another room targeted adolescents and young adults: indeed, the role of social isolation and loneliness in children and adolescents has already been tested, finding associations with lower mental health (particularly depression), physical health problems, and neurodevelopmental conditions (Loades et al., 2020; Benzi et al., 2021). Thus, given the lack of friends' support and stability in their daily routines, especially in a crucial developmental stage where they develop a stable and coherent sense of self, psychological support is crucial (Preti et al., 2015; Benzi, Sarno, \& Di Pierro, 2018; Benzi, Preti, Di Pierro, Clarkin \& Madeddu, 2019; Di Pierro, Gargiulo, Poggi, Madeddu, \& Preti, 2020). The use of digital tools in preadolescent and adolescent populations has recently been tested, leading to 
significant improvements in their mental health (Gladstone et al., 2020; Saulsberry et al., 2013; Wahlund et al., 2020), even in the context of single-session interventions (Schleider et al., 2020).

Fourth, we tailored a room for pregnant women: pregnancy is a complex experience where a need to restructure physical self-image emerges, whilst dealing with physiological and hormonal level changes, and the need to mentalize new fantasies and fears about the unborn child (De Carli et al., 2019). Recent studies highlighted how new technologies are useful for reducing depressive, anxious, and stressful states in this specific population (Felder, Epel, Neuhaus, Krystal, \& Prather, 2020; Shahsavan, Akbari, Gharraee, Abolghasemi, \& Khedmat, 2020).

Fifth, we tailored a room for the general population, as emerging literature showed that the pandemic significantly increased post-traumatic stress symptoms, confusion, and anger (Brooks et al., 2020). The efficacy of online interventions, particularly for anxiety and depression, has already been established (see above).

Finally, we included a room for individuals who contracted COVID-19, both those symptomatic and those without symptoms, and quarantined individuals. For those who are positive and who are facing this particular challenge, both physically and mentally, the efficacy of webbased interventions has already been demonstrated (Wei et al., 2020; Zhou et al., 2020).

\section{Methods}

\section{Participants and procedure}

Participants were recruited through ads on social networks, news reports, and radio announcements. The service had proven to be well-received by the community, with a trend of increasing users, primarily when Lombardy was categorized as a 'red zone' (high emergency status). It is of note that participants used the platform not only at a regional but also at a national level.

Participation in the study comprised two phases: an initial assessment to collect demographics, COVID-19 related topics, standardized measures for anxiety, depression, stress, emotion regulation, and perceived social support (T0; immediately before the treatment); a second survey to assess satisfaction and usability right after the first online intervention (T1; after the intervention). Participation in the research was completely voluntary and dropout was possible at any time. The study was performed in agreement with the Helsinki Declaration of 1975 , as revised in 2000 , and was previously approved by the Ethical Committee in charge (prot. n. 0048092/20).

In less than 3 months, more than 2.000 users created an individual profile, while about 607 users signed up for clinical groups. 134 participants took part in the study at baseline (T0), while 54 rated their perception of the app usability (T1).
Overall, the study involved a community sample of 134 participants with a mean age of 33.20 [standard deviation $(\mathrm{SD})=10.61$, age-range $18-58]$, represented mostly by females $(\mathrm{N}=115 ; 86 \%) .93 .3 \%$ of the sample was of Italian nationality, and $21.6 \%$ lived in Milan, followed by Rome (8.2\%), and Naples and Turin (both 6\%). The majority of the sample was married or had a partner (62\%), whereas $32.8 \%$ were single. Only six individuals were divorced or separated, and only one was a widower. Moreover, most of the sample was represented by students (28.4\%), followed by full-time employed (26.9\%) and unemployed (19.4\%) individuals. The majority of the participants declared a university degree or higher $(\mathrm{N}=77$; $57.4 \%$ ), whereas the remaining participants reported a high-school level of education or below ( $\mathrm{N}=57 ; 42.6 \%)$. Interestingly, $66.4 \%$ of users enrolled in mental health treatments in the past $(\mathrm{N}=89)$, mostly due to anxiety or depression-related symptoms ( $\mathrm{N}=44,31.9 \%) .22 .4 \%$ of respondents reported having tested positive for the virus in the past month, while 3\% reported waiting for their results.

Among participants, a high number had severe up to extremely severe preoccupations for the infection rate (93.3\%), for symptomatology (70\%), for the social impact of the pandemic (92.5\%), and its economic consequences (94.8\%). Moreover, many individuals spent a significant amount of time searching for information on COVID-19: about half of the sample consulted more than once a day news sites $(51.7 \%)$ and social media $(47.5 \%)$ or used phone calls and text messages (42.6\%). One-third of the sample (34.3\%) used television and radio more than once a day to get extra information. The majority of participants $(81.2 \%)$ declared they felt moderate to severe anxiety after consulting the television or radio, as did those who searched websites $(85.9 \%)$. Several participants $(71.6 \%)$ reported they felt moderate to severe anxiety after gathering information from social media, and $73.2 \%$ showed similar anxiety levels after gathering information from phone calls and mobile phone messages. Means and standard deviations of the variables of interest are reported in Table 1.

\section{Measures}

All measures were prompted/administered via the ITA app, available both on iOS and Android systems.

We explored sociodemographic status via age, sex, ethnicity, education level, employment, income, location, and family status.

COVID-19 related information encompassed past psychiatric or psychological consultations, COVID-19 infection or symptomatology both participant or his/her family, concerns and preoccupations regarding COVID-19 symptoms, mortality, contagion and socioeconomic consequences, time spent gathering information about the virus and related psychological distress.

Psychopathological outcomes were assessed via the de- 
pression anxiety stress scales-21 (DASS-21) (Lovibond \& Lovibond, 1995; Italian version Bottesi et al., 2015). The DASS-21 is a 21 items self-report measure assessing emotional distress with three subscales: depression scale, anxiety scale, and stress scale. Participants were asked to rate how much the items applied to them over the past week on a 4-point scale $(0=$ did not apply to me at all, $3=$ applied to me very much or most of the time). Cut-off scores for mild to extremely severe clinical levels are 10-13 for depression, 8-9 for anxiety, and 15-18 for stress after multiplying the participants' scores by two (Lovibond \& Lovibond, 1995). The three DASS-21 scales showed good internal consistency in our sample (range $\alpha=0.93-0.94$ ).

Emotional regulation strategies were assessed by the emotional regulation questionnaire (ERQ) (Gross \& John, 2003; Italian version Balzarotti, John, \& Gross, 2010), a 10 items self-report measure ranging on a 7-point scale ( $1=$ Strongly disagree, $7=$ Strongly agree), rating a higher presence of a specific emotion regulation strategy. The ERQ assesses the ability to manage emotions through two different processes: Cognitive Reappraisal (CR) and Expressive Suppression (ES). CR indicates a cognitive effort to decrease the impact of an emotion-eliciting situation or experience it more positively. ES suggests the attempt to inhibiting the expressive behavior in an emotion-eliciting case. Both scales showed acceptable internal consistency in our sample (CA: $\alpha=0.87$; ES: $\alpha=0.62$ ).

Social support was measured by the Multidimensional Scale of Perceived Social Support (MSPSS; Zimet, Dahlem, Zimet, \& Farley, 1988; Italian version Di Fabio \& Palazzeschi, 2015), which assesses several sources of social support, namely Family, Friends and Significant Other. Participants rated on a 7-point scale $(1=$ Very strongly agree, $7=$ Very strongly disagree) their agreement with twelve different statements (the higher the score, the higher the perceived social support). The three MSPSS scales showed good internal consistency in our sample (range $\alpha=0.85-0.90$ ).
Users' experience was assessed by the system usability scale (SUS) (Brooke, 1996; Italian version Borsci, Federici, \& Lauriola, 2009), a 10 items questionnaire, ranging on a 5-point scale from 1 (Strongly agree) to 5 (Strongly disagree). The measure evaluates the users' perception of usability of several kinds of hardware, software, mobile devices, websites and applications. The SUS showed good internal consistency in our sample $(\alpha=0.84)$.

\section{Statistical analyses}

All analyses were performed using SPSS 26.0 (IBM 2019). Descriptive statistics were conducted to describe the sociodemographic characteristics of the participants. T-test analyses were conducted to investigate gender differences in all variables of interest. Correlation coefficients were calculated to investigate the relationship between emotion regulation strategies, psychological distress and perceived social support.

\section{Results}

The majority of the sample reported experiencing clinically relevant levels of symptomatology, that is, a degree of emotional distress above 78-87 percentile in community samples, as reported by Lovibond \& Lovibon (1995) and Henry \& Crawford (2005): 85\% reported mild up to extremely severe depression indicators, $72 \%$ declared to suffer from anxiety mildly up to severely, $83 \%$ of the sample reported mild up to extremely severe levels of stress. Specifically, people experiencing clinically significant levels of emotional distress on the DASS-21 report dysphoria, hopelessness, devaluation of life, self-deprecation, lack of interest/involvement, anhedonia, and inertia, limited to depressive areas (Lovibond \& Lovibond, 1995). Moreover, our participants experienced autonomic arousal, skeletal muscle effects, situational anxiety, and subjective experience of anxious affect, worries and panic

Table 1. Means and standard deviations of mental health outcome and responses to stress $(\mathrm{N}=134)$.

\begin{tabular}{lcccc}
\hline & M & SD & Min & Max \\
\hline ERQ_COGN_REAPPRAISAL & 27.41 & 7.84 & 7.00 & 42.00 \\
\hline ERQ_EXPRESSIVE_SUPPRESSION & 13.07 & 4.96 & 4.00 & 28.00 \\
\hline DASS_DEPR & 10.93 & 5.59 & 0.00 & 21.00 \\
\hline DASS_ANX & 7.08 & 4.89 & 0.00 & 20.00 \\
\hline DASS_STRESS & 12.24 & 4.48 & 0.00 & 21.00 \\
\hline SSP_FAM & 9.46 & 5.02 & 3.00 & 21.00 \\
\hline SSP_FRIENDS & 12.96 & 6.14 & 4.00 & 28.00 \\
\hline SSP_SIGNIFICANT_OTHER & 11.01 & 7.01 & 4.00 & 28.00 \\
\hline SUS_TOT & 88.98 & 13.56 & 27.5 & 100
\end{tabular}

M, mean; SD, standard deviation; ERQ COGN REAPPRAISAL, cognitive reappraisal scale (ERQ); ERQ EXPRESSIVE SUPPRESSION, expressive suppression scale (ERQ); DASS DEPR, depression scale (DASS-21); DASS_ANX, anxiety scale (DASS-21); DASS_STRESS, stress scale (DASS-21); SSP_FAM, family scale (MSPSS); SSP_FRIENDS, friends scale (MSPSS); SSP_SIGNIFICANT_OTHER, significant other scale (MSPSS); SUS_TOT, SUS global scale. 
(Lovibond \& Lovibond, 1995). Finally, our participants reported a significant level of chronic non-specific arousal, namely difficulty in relaxing, nervous arousal, and the tendency to be upset/agitated, irritable/over-reactive and impatient (Lovibond \& Lovibond, 1995).

Furthermore, we conducted Mann-Withney analyses to investigate gender differences within mental health outcomes and responses to stress (Table 2). Still, we found no significant effect except for depressive and anxious symptomatology which resulted higher in the male sample $(\mathrm{P}<0.05)$. Also, we conducted T-test analyses to explore differences between people with or without previous mental treatments in various mental health outcomes and responses to stress: data yielded to find no significant results $(\mathrm{P}>0.05)$.

In Table 3 we report correlations between psychological negative responses to COVID-19 and possible coping strategies, namely social support and emotional regulation strategies. Results showed that the higher perceived social support, the higher the tendency to suppress emotions. Moreover, the cognitive reappraisal strategy was negatively associated with depression, anxiety, and stress.

Concerning the app usability, overall user experience scored 88.98 ( $\mathrm{SD}=13.56)$, which is considered above the 96 percentile, and it is categorized as 'Best possible'.

\section{Discussion and Conclusions}

The ITA project represents an innovative approach to psychological well-being that facilitates mental health professionals' access for individuals with psychological distress. It also facilitates the link between citizens and mental health services, a connection that is often difficult when there is no immediate hospitalization. Indeed, it is of note that the sample enrolled in our study sought men-

Table 2. Gender differences in mental health outcomes and responses to stress $(\mathrm{N}=134)$.

\begin{tabular}{lcccc}
\hline & $\begin{array}{c}\text { Male } \\
\text { Mean rank }\end{array}$ & $\begin{array}{c}\text { Female } \\
\text { Mean rank }\end{array}$ & $\boldsymbol{U}$ & $\boldsymbol{z}$ \\
\hline ERQ_COGN_REAPPRAISAL & 61.87 & 68.42 & 985.50 & -0.68 \\
\hline ERQ_EXPRESSIVE_SUPPRESSION & 75.34 & 66.20 & 943.50 & -0.95 \\
\hline DASS_DEPR & 84.18 & 64.74 & 775.50 & $-2.02^{*}$ \\
\hline DASS_ANX & 85.71 & 64.49 & 746.50 & $-2.12^{*}$ \\
\hline DASS_STRESS & 80.29 & 65.39 & 849.50 & -1.56 \\
\hline SSP_FAM & 66.47 & 67.67 & 1073.00 & -0.12 \\
\hline SSP_FRIENDS & 77.66 & 65.82 & 899.50 & -1.23 \\
\hline SSP_SIGNIFICANT_OTHER & 79.21 & 65.57 & 870.00 & -1.43 \\
\hline
\end{tabular}

ERQ_COGN_REAPPRAISAL, cognitive reappraisal scale (ERQ); ERQ_EXPRESSIVE_SUPPRESSION, expressive suppression scale (ERQ); DASS_DEPR, depression scale (DASS-21); DASS_ANX, anxiety scale (DASS-21); DASS_STRESS, stress scale (DASS-21); SSP_FAM, family scale (MSPSS); SSP_FRIENDS, friends scale (MSPSS); SSP_SIGNIFICANT_OTHER, significant other scale (MSPSS). ${ }^{*} \mathrm{P}<0.05 ; * * \mathrm{P}<0.01 ; * * * \mathrm{P}<0.001$

Table 3. Correlations among mental health outcome and responses to stress $(\mathrm{N}=134)$.

\begin{tabular}{|c|c|c|c|c|c|c|c|c|c|c|c|}
\hline & 1 & 2 & 3 & 4 & 5 & 6 & 7 & 8 & 9 & 10 & 11 \\
\hline 1. ERQ_COGN_REAPPRAISAL & 1 & & & & & & & & & & \\
\hline 2. ERQ_EXPRESSIVE_SUPPRESSION & -0.11 & 1 & & & & & & & & & \\
\hline 3. DASS_DEPR & $-0.39 * * *$ & 0.13 & 1 & & & & & & & & \\
\hline 4. DASS_ANX & $-0.35^{* * *}$ & 0.10 & $0.58 * * *$ & 1 & & & & & & & \\
\hline 5. DASS_STRESS & $-0.34 * * *$ & 0.042 & $0.75^{* * *}$ & $0.64^{* * *}$ & 1 & & & & & & \\
\hline 6. SSP_FAM & $-0.18^{*}$ & $0.25 * *$ & $0.27 * *$ & $0.17^{*}$ & $0.18^{*}$ & 1 & & & & & \\
\hline 7. SSP_FRIENDS & -0.12 & $0.34 * * *$ & $0.19^{*}$ & 0.12 & 0.07 & $0.47^{* * *}$ & 1 & & & & \\
\hline 8. SSP_SIGNIFICANT_OTHER & -0.05 & $0.28 * *$ & $0.27 * *$ & 0.08 & 0.12 & $0.52^{* * *}$ & $0.52 * * *$ & 1 & & & \\
\hline 9. ERQ_TOT & $0.83 * * *$ & $0.46^{* * *}$ & $-0.27 * *$ & $-0.26^{* *}$ & $-0.28^{* *}$ & -0.02 & 0.09 & 0.11 & 1 & & \\
\hline 10. DASS_TOT & $-0.41 * * *$ & 0.11 & $0.90^{* * *}$ & $0.84 * * *$ & $0.90^{* * *}$ & $0.24 * *$ & 0.15 & $0.18^{*}$ & $-0.31 * * *$ & 1 & \\
\hline 11. SSP_TOT & -0.14 & $0.36^{* * *}$ & $0.30^{* *}$ & 0.14 & 0.14 & $0.77^{* * *}$ & $0.81^{* * *}$ & $0.86^{* * *}$ & 0.08 & $0.23 * *$ & 1 \\
\hline
\end{tabular}

ERQ COGN REAPPRAISAL, cognitive reappraisal scale (ERQ); ERQ EXPRESSIVE SUPPRESSION, expressive suppression scale (ERQ); DASS DEPR, depression scale (DASS-21); DASS_ANX, anxiety scale (DASS-21); DASS_STRESS, stress scale (DASSS-21); SSP_FAM, family scale (MSPSS); SSP_FRIENDS, friends scale (MSPSS); SSP_SIGNIFICANT_OTHER, significant other scale (MSPSS); ERQ_TOT, ERQ global scale; DASS_TOT, DASS-21 global scale; SSP_TOT, MSPSS global scale. *P ${ }^{2}<0.05 ;{ }^{*} * \mathrm{P}<0.01 ; * * * \mathrm{P}<0.001$. 
tal health treatment in the past, in particular, due to anxiety or depression-related symptoms. This result is in line with previous findings, highlighting how the personal history of psychiatric symptoms is a risk factor for mental health distress in response to COVID-19 emergency (for a review, see Luo, Guo, Yu, Jiang, \& Wang, 2020; Stein, 2020). In line with this assumption, many authors underlined the importance of taking care of psychiatric patients in the pandemic framework (Xiao et al., 2020; Zhu et al., 2020 ), considering them as a vulnerable target-population (Yao et al., 2020).

Interestingly, most of the participants showed to be particularly scared of economic consequences, followed by infection rate, the pandemic's social impact, and symptomatology, in line with previous studies highlighting higher economic anxiety levels than health anxiety (Bareket-Bojmel, Shahar, \& Margalit, 2020). Overall, most of our sample reported significant clinical levels of depression, anxiety, and stress concerning psychological distress levels. Surely, our data emphasize the need to develop a service that considers psychological well-being in times of pandemic, not only for those with a psychiatric history but also for the whole population who have to face economic, social, and health uncertainty. Moreover, we found that participants consulted more than once different media, particularly news sites and social media, followed by phone calls and text messages, and television and radio. Consistent with previous studies, this is related to experiencing significant anxiety levels after being exposed to COVID-19-related information (Neria \& Sullivan, 2011; Gao et al., 2020).

Furthermore, we found no significant gender differences between our interest variables, except for men who reported higher levels of depression than women. This result is consistent with previous findings by Gong, Xie, $\mathrm{Xu}, \&$ Yuejia (2010) and Jiang et al. (2020), where men experienced higher depression levels than women. Nevertheless, our result could be affected by the low number of male subjects who took part in our study ( $\mathrm{N}=19)$.

Overall, the ITA service seems to intercept people who present clinically significant difficulties and struggle to implement effective emotional regulation strategies.

Indeed, preliminary data showed significant associations between expressive suppression strategies and perceived social support. Specifically, we found evidence that people experiencing low support tend to suppress their emotions. Our finding is consistent with previous findings, showing that expressive suppression is related to lower social support, fewer significant relationships, disruption in social communication, inhibition tendency, and feelings of inauthenticity (Butler et al., 2003; Chukwuorji, Uzuegbu, Chukwu, Ifeagwazi, \& Ugwu, 2020; Gross \& John, 2003; Srivastava, Tamir, McGonigal, John, \& Gross., 2009; Joormann \& Gotlib, 2010; Cutuli, 2014). Expressive suppression is a coping strategy that involves the inhibition of one's emotional expressivity and emo- tional dysregulation (Butler et al., 2003). Consistently with this conceptualization, we found evidence that expressive suppression has no buffer role toward psychological distress, as in the study by d'Arbeloff et al. (2018). Indeed, expressive suppression did not show significant correlations with any DASS-21 subscales.

On the contrary, we found the already established buffering role of cognitive reappraisal toward psychological distress in several studies (e.g., Preece, Becerra, Robinson, \& Gross, 2020), in particular regarding depression and anxiety (Gross \& John, 2003; Cutuli, 2014). Moreover, our result is in line with previous findings showing that people using cognitive reappraisal tend to have higher self-esteem and well-being (Joormann \& Gotlib, 2010). Cognitive reappraisal consists of mental processes helping to make sense of negative emotions, so it is not surprising that it has been found to decrease mental health distress in our study.

Regarding usability, we found that ITA has increasingly become a new resource for citizens and the community, both at the regional and national levels. Participants reported a general satisfaction, described the app as intuitive, easy to use, innovative, and qualitatively reported a more substantial positive effect for larger groups. Among the peculiar characteristics of the app, participants reported several perks: the direct link with a professional therapist, the quality of the psychological treatments, the delivery of the service via standard devices, such as smartphones and tablets, the direct network with the regional territory, the gratuity of the service during a time in which the health emergency has hit the entire population and, finally, the possibility to get a remote consultation, which resulted fundamental in the framework of fragile population groups, positive/quarantined people or individuals from high emergency areas.

The results of this study can be better understood in the context of its limitations. First, the gap between the number of people that downloaded the app and those who completed the survey should be considered in discussing user satisfaction: only satisfied users might have been willing to provide information on their experience. However, other possible confounding variables might be helpful to consider: the participation in the survey was prompted only once via the app, and that might not have been a sufficient incentive; also, like in any clinical context, the desire to keep the experience as private as possible might have played a role. Moreover, data display an initial picture of the participants, and correlations might hide the need to investigate a higher level of complexity between the variables gathering longitudinal data and performing further analyses (such as multiple regression and mediation/moderation models).

Overall, this initial picture is sharp enough to support the urgent need to develop an intervention that can meet the newest demands arising from the COVID-19 pandemic outbreak. Moreover, our findings highlight the need 
for new tools that can facilitate individuals' access to mental health professionals. Psychological support might be crucial to help participants to increase their cognitive reelaboration of a traumatic experience. Psychological support might play a key role in expressing their emotions instead of suppressing them, which is even more crucial in high-stress times. Finally, an easy-to-use app like ITA might provide a quick and convenient place for people to access professional support and counseling.

\section{References}

Agyapong, V. (2020). Coronavirus disease 2019 pandemic: health system and community response to a text message (Text4Hope) program supporting mental health in Alberta. Disaster Medicine and Public Health Preparedness, 14(5), E5-E6. http://doi.org/10.1017/dmp.2020.114

Balzarotti, S., John, O. P., \& Gross, J. J. (2010). An Italian adaptation of the emotion regulation questionnaire. European Journal of Psychological Assessment, 26(1), pp. 61-67. https://doi.org/10.1027/1015-5759/a000009

Banbury, A., Nancarrow, S., Dart, J., Gray, L., \& Parkinson, L. (2018). Telehealth interventions delivering home-based support group videoconferencing: systematic review. Journal of Medical Internet Research, 20(2), e25. https://doi.org/ 10.2196/jmir. 8090

Bareket-Bojmel, L., Shahar, G., \& Margalit, M. (2020). COVID19-related economic anxiety is as high as health anxiety: findings from the USA, the UK, and Israel. International journal of cognitive therapy, 1-9. Advance online publication. https://doi.org/10.1007/s41811-020-00078-3

Ben-Zeev, D., Buck, B., Meller, S., Hudenko, W. J., \& Hallgren, K. A. (2020). Augmenting evidence-based care with a texting mobile interventionist: a pilot randomized controlled trial. Psychiatric Services, 71(12), 1218-1224. https://doi. org/10.1176/appi.ps.202000239

Benzi, I., Di Pierro, R., De Carli, P., Cristea, I. A., \& Cipresso, P. (2020). All the faces of research on borderline personality pathology: drawing future trajectories through a network and cluster analysis of the literature. Journal of EvidenceBased Psychotherapies, 20(2). http://doi.org/10.24193/ jebp.2020.2.9

Benzi, I. M. A., Fontana, A., Di Pierro, R., Perugini, M., Cipresso, P., Madeddu, F., Clarkin, J. F., \& Preti, E. (2021). Assessment of personality functioning in adolescence: development of the adolescent personality structure questionnaire. Assessment. Advance online publication. https://doi. org/10.1177/1073191120988157

Benzi, I. M. A., Milesi, A., Parolin, L. A. L. (2021). Unconscious in Psychology. In: Glăveanu V.P. (Eds). The Palgrave Encyclopedia of the Possible. Palgrave Macmillan, Cham. https://doi.org/10.1007/978-3-319-98390-5_162-1

Benzi, I. M., Preti, E., Di Pierro, R., Clarkin, J. F., \& Madeddu, F. (2019). Maladaptive personality traits and psychological distress in adolescence: The moderating role of personality functioning. Personality and Individual Differences, 140, 33-40. http://doi.org/10.1016/j.paid.2018.06.026

Benzi, I., Sarno, I., \& Di Pierro, R. (2018). Maladaptive personality functioning and non-suicidal self-injury in adolescence. Clinical Neuropsychiatry, 15(4).

Borsci, S., Federici, S., \& Lauriola, M. (2009). On the dimensionality of the System Usability Scale: a test of alternative measurement models. Cognitive processing, 10(3), 193-197. https://doi.org/10.1007/s10339-009-0268-9

Bottesi, G., Ghisi, M., Altoè, G., Conforti, E., Melli, G., Sica, C. (2015). The Italian version of the Depression Anxiety Stress Scales-21: Factor structure and psychometric properties on community and clinical samples. Comprehensive Psychiatry, 60, 170-181. https://doi.org/10.1016/j. comppsych.2015.04.005

Brooke, J. (1996). SUS: a quick and dirty usability scale. In P. W. Jordan, B. Thomas, B. A. Weerdmeester, A. L. McClelland (Eds.) Usability Evaluation in Industry. London: Taylor and Francis. https://doi.org/10.1177/1541931213571043

Brooks, S. K., Webster, R. K., Smith, L. E., Woodland, L., Wessely, S., Greenberg, N., \& Rubin, G. J. (2020). The psychological impact of quarantine and how to reduce it: rapid review of the evidence. Lancet (London, England), 395(10227), 912-920. https://doi.org/10.1016/S0140-6736 (20)30460-8

Burger, F., Neerincx, M. A., \& Brinkman, W. P. (2020). Technological state of the art of electronic mental health interventions for major depressive disorder: Systematic literature review. Journal of Medical Internet Research, 22(1), e12599. http://doi.org/10.2196/12599

Butler, E. A., Egloff, B., Wilhelm, F. H., Smith, N. C., Erikson, E. A., \& Gross, J. J. (2003). The social consequences of expressive suppression. Emotion, 3, 48-67. https://doi. org/10.1037/1528-3542.3.1.48

Chakrabarti, S. (2015). Usefulness of telepsychiatry: A critical evaluation of videoconferencing- based approaches. World journal of psychiatry, 5(3), 286-304. https://dx.doi.org/ 10.5498\%2Fwjp.v5.i3.286

Cheng, P., Casement, M. D., Kalmbach, D. A., Castelan, A. C., \& Drake, C. L. (2020). Digital cognitive behavioral therapy for insomnia promotes later health resilience during the coronavirus disease 19 (COVID-19) pandemic. Sleep. Advance online publication. http://doi.org/10.1093/sleep/ zsaa258

Chevallard, G., Veronese, G., Giudici, R., Pressato, L., Pozzi F., Compagnone, C., Fossi, F., Bernasconi, F., Curto, F., Zaniboni, M., Bassi, G., Chiara, O., Fumagalli, R., \& Chieregato, A. (2020). Facing increased suicide attempts during COVID-19 pandemic lockdown: the experience from the major trauma center in Lombardy, Italy. Minerva Anestesiologica. Advance online publication. http://dx.doi.org/ 10.23736/S0375-9393.20.14970-8

Chukwuorji, J. C., Uzuegbu, C. N., Chukwu, C. V., Ifeagwazi, C. M., \& Ugwu, C. (2020). Social support serves emotion regulation function in death anxiety among people living with HIV/AIDS. South African Journal of Psychology, 50(3), 395-410. https://doi.org/10.1177/008124631989 4700

Cluver, L., Lachman, J. M., Sherr, L., Wessels, I., Krug, E., Rakotomalala, S., Blight, S., Hillis, S., Bachman, G., Green, O., Butchart, A., Tomlinson, M., Ward, C. L., Doubt, J., \& McDonald, K. (2020). Parenting in a time of COVID-19. Lancet (London, England), 395(10231), e64. https://doi.org/ 10.1016/S0140-6736(20)30736-4

Cutuli, D. (2014). Cognitive reappraisal and expressive suppression strategies role in the emotion regulation: an overview on their modulatory effects and neural correlates. Frontiers in Systems Neuroscience, 8, 175. http://doi.org/10.3389/ fnsys.2014.00175

da Silva, J. A., Siegmund, G., Bredemeier, J. (2015). Crisis interventions in online psychological counseling. Trends in 
Psychiatry and Psychotherapy, 37(4), 171-182. http://dx.doi.org/10.1590/2237-6089-2014-0026

De Carli, P., Tagini, A., Sarracino, D., Santona, A., \& Parolin, L. (2016). Implicit attitude toward caregiving: the moderating role of adult attachment styles. Frontiers in Psychology, 6, 1906. http://doi.org/10.3389/fpsyg.2015.01906

De Carli, P., Costantini, I., Sessa, P., Visentin, S., Pearson, R. M., \& Simonelli, A. (2019). The expectant social mind: A systematic review of face processing during pregnancy and the effect of depression and anxiety. Neuroscience \& Biobehavioral Reviews. Advance online publication. https://doi. org/10.1016/j.neubiorev.2019.04.013

Di Fabio, A., \& Palazzeschi, L. (2015). Multidimensional Scale of Perceived Social Support (MSPSS): un contributo alla validazione italiana [Multidimensional Scale of Perceived Social Support (MSPSS): A contribution to Italian validation]. Counseling: Giornale Italiano di Ricerca e Applicazioni, 8(3), 127-140.

Di Pierro, R., Gargiulo, I., Poggi, A., Madeddu, F., \& Preti, E. (2020). The level of personality functioning scale applied to clinical material from the Structured Interview of Personality Organization (STIPO): utility in detecting personality pathology. Journal of Personality Disorders, 1-15. http://doi.org/10.1521/pedi 2020 34 472

Duan, L., \& Zhu, G. (2020). Psychological interventions for people affected by the COVID-19 epidemic. The Lancet Psychiatry. Advance online publication. https://doi.org/ 10.1016/S2215-0366(20)30073-0

Felder, J. N., Epel, E. S., Neuhaus, J., Krystal, A. D., \& Prather, A. A. (2020). Efficacy of digital cognitive behavioral therapy for the treatment of insomnia symptoms among pregnant women: a randomized clinical trial. JAMA Psychiatry, 77(5), 484-492. https://doi.org/10.1001/jamapsychiatry. 2019.4491

Forsell, E., Bendix, M., Holländare, F., von Schultz, B. S., Nasiell, J., Blomdahl-Wetterholm, M., ... \& Kaldo, V. (2017). Internet delivered cognitive behavior therapy for antenatal depression: A randomised controlled trial. Journal of Affective Disorders, 221, 56-64. https://doi.org/ 10.1016/j.jad.2017.06.013

Henry, J. D., \& Crawford, J. R. (2005). The short-form version of the depression anxiety stress scales (DASS-21): Construct validity and normative data in a large non-clinical sample. British Journal of Clinical Psychology, 44(2), 227-239. https://doi.org/10.1348/014466505X29657

Gao, J., Zheng, P., Jia, Y., Chen, H., Mao, Y., Chen, S., Wang Y., Fu, H., Dai, J. (2020). Mental health problems and social media exposure during COVID-19 outbreak. PLoS One, 15(4), e0231924. http://doi.org/10.1371/journal.pone. 0231924

Gili, M., Castro, A., García-Palacios, A., Garcia-Campayo, J., Mayoral-Cleries, F., Botella, C., ... \& Baños, R. M. (2020). Efficacy of three low-intensity, internet-based psychological interventions for the treatment of depression in primary care: randomized controlled trial. Journal of Medical Internet Research, 22(6), e15845. http://doi.org/10.2196/15845

Gladstone, T., Buchholz, K. R., Fitzgibbon, M., Schiffer, L., Lee, M., \& Voorhees, B. (2020). Randomized clinical trial of an internet-based adolescent depression prevention intervention in primary care: internalizing symptom outcomes. International Journal of Environmental Research and Public Health, 17(21), 7736. https://doi.org/10.3390/ijerph17217736

Gong, X., Xie, X., Xu, R., \& Yuejia, L. (2010). Psychometric properties of the Chinese versions of DASS-21 in Chinese college students. Chinese Journal of Clinical Psychology, 18, 443-446. http://doi.org/10.3389/fpsyg.2020.00247

Gross, J. J., \& John, O. P. (2003). Individual differences in two emotion regulation processes: implications for affect, relationships, and wellbeing. Journal of Personality and Social Psychology, 85(2), 348-362. https://doi.org/10.1037/00223514.85.2.348

Hallgren, M., Kraepelien, M., Lindefors, N., Zeebari, Z., Kaldo, V., \& Forsell, Y. (2015). Physical exercise and internet-based cognitive-behavioural therapy in the treatment of depression: randomised controlled trial. The British Journal of Psychiatry, 207(3), 227-234. https://doi.org/10.1192/bjp.bp.114.160101

Jiang, L. C., Yan, Y. J., Jin, Z. S., Hu, M. L., Wang, L., Song, Y., Li, N. N., Su, J., Wu, D. X., \& Xiao, T. (2020). The depression anxiety stress scale- 21 in Chinese hospital workers: reliability, latent structure, and measurement invariance across genders. Frontiers in Psychology, 11, 247. https://doi.org/10.3389/ fpsyg.2020.00247

Joormann, J., \& Gotlib, I. H. (2010). Emotion regulation in depression: relation to cognitive inhibition. Cognition and Emotion, 24, 281-298. http://doi.org/10.1080/02699930903 407948

Kang, L., Ma, S., Chen, M., Yang, J., Wang, Y., Li, R., Yao, L., Bai, H., Cai, Z., Xiang Yang, B., Hu, S., Zhang, K., Wang, G., Ma, C., \& Liu, Z. (2020). Impact on mental health and perceptions of psychological care among medical and nursing staff in Wuhan during the 2019 novel coronavirus disease outbreak: A cross-sectional study. Brain, Behavior, and Immunity, 87, 11-17. https://doi.org/10.1016/j.bbi.2020.03.028

Kladnitski, N., Smith, J., Uppal, S., James, M. A., Allen, A. R., Andrews, G., \& Newby, J. M. (2020). Transdiagnostic internet-delivered CBT and mindfulness-based treatment for depression and anxiety: A randomised controlled trial. Internet Interventions, 20, 100310. http://doi.org/10.1016/ j.invent.2020.100310

Kubo, A., Kurtovich, E., McGinnis, M., Aghaee, S., Altschuler, A., Quesenberry Jr, C., ... \& Avins, A. (2020). Pilot pragmatic randomized trial of mHealth mindfulness-based intervention for advanced cancer patients and their informal caregivers. Psycho-Oncology. Advance online publication. https://doi.org/10.1177/1534735419850634

Lindegaard, T., Hesslow, T., Nilsson, M., Johansson, R., Carlbring, P., Lilliengreen, P., Andersson, G. (2020). Internetbased psychodynamic therapy vs cognitive behavioural therapy for social anxiety disorder: A preference study. Internet Interventions, 1-9. https://doi.org/10.1016/j.invent. 2020.100316

Lis, A., Parolin, L., Calvo, V., Zennaro, A., \& Meyer, G. (2007). The impact of administration and inquiry on Rorschach Comprehensive System protocols in a national reference sample. Journal of Personality Assessment, 89(S1), S193-S200.

Liu, S., Yang, L., Zhang, C., Xiang, Y. T., Liu, Z., Hu, S., \& Zhang, B. (2020). Online mental health services in China during the COVID-19 outbreak. The Lancet Psychiatry. Advance online publication. https://doi.org/10.1016/S22150366(20)30077-8

Loades, M. E., Chatburn, E., Higson-Sweeney, N., Reynolds, S., Shafran, R., Brigden, A., Linney, C., McManus, M. N., Borwick, C., \& Crawley, E. (2020). Rapid systematic review: the impact of social isolation and loneliness on the mental health of children and adolescents in the context of COVID-19. Journal of the American Academy of Child and Adolescent Psychiatry, 59(11), 1218-1239.e3. https://doi.org/ 10.1016/j.jaac.2020.05.009 
Lopez, R., Evangelista, E., Barateau, L., Chenini, S., Bosco, A., Billiard, M., ... \& Dauvilliers, Y. (2019). French language online cognitive behavioral therapy for insomnia disorder: a randomized controlled trial. Frontiers in Neurology, 10, 1273. http://doi.org/10.3389/fneur.2019.01273

Lovibond, P. F., \& Lovibond, S. H. (1995). The structure of negative emotional states: comparison of the depression anxiety stress scales (DASS) with the beck depression and anxiety inventories. Behaviour Research and Therapy, 33(3), 335-343. https://doi.org/10.1016/0005-7967(94)00075-u

Luo, M., Guo, L., Yu, M., Jiang, W., \& Wang, H. (2020). The psychological and mental impact of coronavirus disease 2019 (COVID-19) on medical staff and general public - A systematic review and meta-analysis. Psychiatry Research, 291, 113190. https://doi.org/10.1016/j.psychres.2020.113190

Marziali, E., Damianakis, T., \& Donahue, P. (2006) Internet-based clinical services: virtual support groups for family caregivers. Journal of Technology in Human Services, 24, 2-3, 39-54. https://doi.org/10.1300/J017v24n02_03

Matiz, A., Fabbro, F., Paschetto, A., Cantone, D., Paolone, A. R., \& Crescentini, C. (2020). Positive impact of mindfulness meditation on mental health of female teachers during the COVID-19 outbreak in Italy. International Journal of Environmental Research and Public Health, 17(18), 6450. http://doi.org/10.3390/ijerph17186450

Mazza, C., Ricci, E., Biondi, S., Colasanti, M., Ferracuti, S., Napoli, C., \& Roma, P. (2020). A nationwide survey of psychological distress among italian people during the COVID19 pandemic: Immediate psychological responses and associated factors. International Journal of Environmental Research and Public Health, 17(9), 3165. http://doi.org/ 10.3390/ijerph17093165

Miller, C. B., Gu, J., Henry, A. L., Davis, M. L., Espie, C. A., Stott, R., ... \& Carl, J. R. (2021). Feasibility and efficacy of a digital CBT intervention for symptoms of Generalized Anxiety Disorder: A randomized multiple-baseline study. Journal of Behavior Therapy and Experimental Psychiatry, 70, 101609. http://doi.org/10.1016/j.jbtep.2020.101609.

Miralles, I., Granell, C., Díaz-Sanahuja, L., Van Woensel, W., Bretón-López, J., Mira, A., Castilla, D., \& Casteleyn, S. (2020). Smartphone apps for the treatment of mental disorders: systematic review. JMIR mHealth and uHealth, 8(4), e14897. https://doi.org/10.2196/14897.

Neria, Y., Sullivan, G. M. (2011). Understanding the mental health effects of indirect exposure to mass trauma through the media. JAMA, 306(12), 1374-1375. http://doi.org/10.1001/jama. 2011.1358

Nissen, E. R., O’Connor, M., Kaldo, V., Højris, I., Borre, M., Zachariae, R., \& Mehlsen, M. (2020). Internet-delivered mindfulness-based cognitive therapy for anxiety and depression in cancer survivors: A randomized controlled trial. Psycho-oncology, 29(1), 68-75. http://doi.org/10.1002/ pon. 5237

Percudani, M., Corradin, M., Moreno, M., Indelicato, A., \& Vita, A. (2020). Mental Health Services in Lombardy during COVID-19 outbreak. Psychiatry Research, 288, 112980. https://doi.org/10.1016/j.psychres.2020.112980

Petzold, M. B., Bendau, A., Plag, J., Pyrkosch, L., Mascarell Maricic, L., Betzler, F., Rogoll, J., Große, J., \& Ströhle, A. (2020). Risk, resilience, psychological distress, and anxiety at the beginning of the COVID-19 pandemic in Germany. Brain and Behavior, 10(9), e01745. https://doi.org/10.1002/brb3.1745

Pizzoli, S. F. M., Marzorati, C., Mazzoni, D., \& Pravettoni, G. (2020). Web-based relaxation intervention for stress during social isolation: randomized controlled trial. JMIR Mental Health, 7(12), e22757. http://doi.org/10.2196/22757

Preece, D. A., Becerra, R., Robinson, K., \& Gross, J. J. (2020). The emotion regulation questionnaire: psychometric properties in general community samples. Journal of Personality Assessment, 102(3), 348-356. https://doi.org/10.1080/ 00223891.2018 .1564319

Preti, E., Di Mattei, V., Perego, G., Ferrari, F., Mazzetti, M., Taranto, P., Di Pierro, R., Madeddu, F., \& Calati, R. (2020). The psychological impact of epidemic and pandemic outbreaks on healthcare workers: rapid review of the evidence. Current Psychiatry Reports, 22(8), 43. https://doi.org/10.1007/s11920-020-01166-Z

Preti, E., Di Pierro, R., Fanti, E., Madeddu, F., \& Calati, R. (2020). Personality disorders in time of pandemic. Current Psychiatry Reports, 22(12), 80. https://doi.org/10.1007/s11920-02001204-w

Preti, E., Prunas, A., De Panfilis, C., Marchesi, C., Madeddu, F., \& Clarkin, J. F. (2015). The facets of identity: Personality pathology assessment through the Inventory of Personality Organization. Personality Disorders: Theory, Research, and Treatment, 6(2), 129-140. https://doi.org/10.1037/per0000119

Qiu, J., Shen, B., Zhao, M., Wang, Z., Xie, B., \& Xu, Y. (2020). A nationwide survey of psychological distress among Chinese people in the COVID-19 epidemic: implications and policy recommendations. General Psychiatry, 33(2), e100213. https://doi.org/10.1136/gpsych-2020-100213

Querstret, D., Cropley, M., \& Fife-Schaw, C. (2018). The effects of an online mindfulness intervention on perceived stress, depression and anxiety in a non-clinical sample: a randomised waitlist control trial. Mindfulness, 9(6), 1825-1836. https://doi.org/10.1007/s12671-018-0925-0

Rapisarda, F., Vallarino, M., Cavallini, E., Barbato, A., BrousseauParadis, C., De Benedictis, L., \& Lesage, A. (2020). The early impact of the Covid-19 emergency on mental health workers: a survey in Lombardy, Italy. International Journal of Environmental Research and Public Health, 17(22), 8615. https://doi.org/10.3390/ijerph17228615

Räsänen, P., Lappalainen, P., Muotka, J., Tolvanen, A., \& Lappalainen, R. (2016). An online guided ACT intervention for enhancing the psychological wellbeing of university students: A randomized controlled clinical trial. Behaviour Research and Therapy, 78, 30-42. https://doi.org/10.1016/j.brat. 2016.01.001

Richardson, L. K., Christopher Frueh, B., Grubaugh, A. L., Egede, L., \& Elhai, J. D. (2009). Current directions in videoconferencing tele-mental health research. Clinical Psychology: Science and Practice, 16(3), 323-338. https://doi.org/10.1111/ j.1468-2850.2009.01170.x

Ritvo, P., Ahmad, F., El Morr, C., Pirbaglou, M., \& Moineddin, R. (2020). Randomized controlled trial of mindfulness-based intervention for student depression, anxiety and stress: observations on a disrupted campus. JMIR Mental Health. Advance online publication. http://doi.org/10.2196/23491

Romero, C.S., Delgado, C., Català, J., Ferrer, C., Errando, C., Iftimi, A., Benito, A., de Andrés, J., Otero, M., \& the PSIMCOV Group. (2020). COVID-19 psychological impact in 3109 healthcare workers in Spain: The PSIMCOV group. Psychological Medicine, 1-7. Advance online publication. https://doi.org/10.1017/S0033291720001671

Saulsberry, A., Marko-Holguin, M., Blomeke, K., Hinkle, C., Fogel, J., Gladstone, T., Bell, C., Reinecke, M., Corden, M., \& Van Voorhees, B. W. (2013). Randomized clinical trial of a primary care internet-based intervention to prevent adolescent 
depression: one-year outcomes. Journal of the Canadian Academy of Child and Adolescent Psychiatry, 22(2), 106-117.

Schleider, J. L., Dobias, M., Sung, J., Mumper, E., \& Mullarkey, M. C. (2020). Acceptability and Utility of an Open-Access, Online Single-Session Intervention Platform for Adolescent Mental Health. JMIR Mental Health, 7(6), e20513. https://doi.org/10.2196/20513

Schure, M., McCrory, B., Franklin, K. T., Greist, J., \& Weissman, R. S. (2020). Twelve-month follow-up to a fully automated internet-based cognitive behavior therapy intervention for rural adults with depression symptoms: single-arm longitudinal study. Journal of Medical Internet Research, 22(10), e21336. http://doi.org/ 10.2196/21336

Segal, Z. V., Dimidjian, S., Beck, A., Boggs, J. M., Vanderkruik, R., Metcalf, C. A., ... \& Levy, J. (2020). Outcomes of online mindfulness-based cognitive therapy for patients with residual depressive symptoms: a randomized clinical trial. JAMA Psychiatry, 77(6), 563-573. http://doi.org/10.1001/jamapsychiatry.2019.4693

Shahsavan, F., Akbari, N., Gharraee, B., Abolghasemi, J. \& Khedmat, L. (2020). The effect of internet-based guided self-help cognitive-behavioral therapies on Iranian women' psychological symptoms and preferred method of childbirth. Perspectives in Psychiatric Care. Advance online publication. https://doi.org/10.1111/ppc.12535.

Shankland, R., Tessier, D., Strub, L., Gauchet, A., \& Baeyens, C. (2020). Improving mental health and well-being through informal mindfulness practices: an intervention study. Applied Psychology: Health and Well-Being. Advance online publication. http://doi.org/10.1111/aphw.12216

Soklaridis, S., Lin, E., Lalani, Y., Rodak, T., Sockalingam, S. (2020) Mental health interventions and supports during COVID-19 and other medical pandemics: A rapid systematic review of the evidence. General Hospital Psychiatry, 66, p. 133-146. https://doi.org/10.1016/j.genhosppsych.2020.08.007

Srivastava, S., Tamir, M., McGonigal, K. M., John, O. P., \& Gross, J. J. (2009). The social costs of emotional suppression: A prospective study of the transition to college. Journal of Personality and Social Psychology, 96(4), 883-897. https://doi. org/10.1037/a0014755

Stein, M. B. (2020) Coronavirus disease 2019 (COVID-19): psychiatric illness. In: UpToDate, Post TW (Ed), UpToDate, Waltham, MA.

Stroebe, M., \& Schut, H. (2020). Bereavement in times of COVID-19: a review and theoretical framework. Omega, 30222820966928. Advance online publication. https://doi.org/ $10.1177 / 0030222820966928$

Tan, B., Chew, N., Lee, G., Jing, M., Goh, Y., Yeo, L., Zhang, K., Chin, H. K., Ahmad, A., Khan, F. A., Shanmugam, G. N., Chan, B., Sunny, S., Chandra, B., Ong, J., Paliwal, P. R., Wong, L., Sagayanathan, R., Chen, J. T., Ng, A., ... Sharma, V. K. (2020). Psychological Impact of the COVID-19 Pandemic on Health Care Workers in Singapore. Annals of Internal Medicine, 173(4), 317-320. https://doi.org/10.7326/M20-1083

Taquet, M., Luciano, S., Geddes, J. R., Harrison, P. J. (2020). Bidirectional associations between COVID-19 and psychiatric disorder: retrospective cohort studies of 62354 COVID-19 cases in the USA, The Lancet Psychiatry. Advance online publication. https://doi.org/10.1016/S22150366(20)30462-4.

Taylor, C., Graham, A. K., Flatt, R. E., Waldherr, K., \& Fitzsimmons-Craft, E. E. (2020). Current state of scientific evidence on Internet-based interventions for the treatment of depression, anxiety, eating disorders and substance abuse: an overview of systematic reviews and meta-analyses. European Journal of Public Health, ckz208. Advance online publication. https://doi.org/10.1093/eurpub/ckz208

Wagner, B., Rosenberg, N., Hofmann, L., \& Maass, U. (2020). Web-based bereavement care: a systematic review and metaanalysis. Frontiers in Psychiatry, 11, 525. https://doi. org/10.3389/fpsyt.2020.00525

Wahlund, T., Jolstedt, M., Andersson, E., Vigerland, S., Perrin, S., Öst, L. G., Högström, J., \& Serlachius, E. (2020). Online cognitive behavior therapy for adolescents with excessive worry: a multiple baseline design feasibility study. mHealth, 6, 5 . https://doi.org/10.21037/mhealth.2019.09.10

Wang, C., Pan, R., Wan, X., Tan, Y., Xu, L., Ho, C. S., \& Ho, R. C. (2020a). Immediate psychological responses and associated factors during the initial stage of the 2019 coronavirus disease (COVID-19) epidemic among the general population in China. International Journal of Environmental Research and Public Health, 17(5), 1729. https://doi.org/ 10.3390/ijerph17051729

Wang, H., Zhao, Q., Mu, W., Rodriguez, M., Qian, M., \& Berger, T. (2020b). The Effect of Shame on Patients With Social Anxiety Disorder in Internet-Based Cognitive Behavioral Therapy: Randomized Controlled Trial. JMIR Mental Health, 7(7), e15797. http://doi.org/10.2196/15797

Wei, N., Huang, B. C., Lu, S. J., Hu, J. B., Zhou, X. Y., Hu, C. C., Chen, J. K., Huang, J. W., Li, S. G., Wang, Z., Wang, D. D., Xu, Y., \& Hu, S. H. (2020). Efficacy of internet-based integrated intervention on depression and anxiety symptoms in patients with COVID-19. Journal of Zhejiang University, Science, $B, \quad 21(5), \quad 400-404$. https://doi.org/10.1631/ jzus.B2010013

Xiao, C., 2020. A novel approach of consultation on 2019 novel coronavirus (COVID-19)-related psychological and mental problems: structured letter therapy. Psychiatry Investig 17, 175-176. https://doi.org/10.30773/pi.2020.0047

Yao, H., Chen, J.-H., Xu, Y.-F. (2020). Patients with mental health disorders in the COVID-19 epidemic. The Lancet Psychiatry 7, e21. https://doi.org/10.1016/S2215-0366(20)30090-0

Zhang, J., Wu, W., Zhao, X., \& Zhang, W. (2020). Recommended psychological crisis intervention response to the 2019 novel coronavirus pneumonia outbreak in China: a model of West China Hospital. Precision Clinical Medicine. https://doi.org/ 10.1093/pcmedi/pbaa006

Zhang, M., \& Smith, H. E. (2020). Digital tools to ameliorate psychological symptoms associated with COVID-19: scoping review. Journal of Medical Internet Research, 22(8), e19706. https://doi.org/10.2196/19706

Zhou, L., Xie, R., Yang, X., Zhang, S., Li, D., Zhang, Y., Liu, J., Pakhale, S., Krewski, D., \& Wen, S. W. (2020). Feasibility and preliminary results of effectiveness of social media-based intervention on the psychological well-being of suspected COVID-19 cases during quarantine. The Canadian Journal of Psychiatry, 65(10), 736-738. https://doi.org/10.1177/ 0706743720932041

Zhu, Y., Chen, L., Ji, H., Xi, M., Fang, Y., \& Li, Y., (2020). The risk and prevention of novel coronavirus pneumonia infections among inpatients in psychiatric hospitals. Neuroscience Bulletin 36, 299-302. https://doi.org/10.1007/s12264-02000476-9

Zimet, G. D., Powell, S. S., Farley, G. K., Werkman, S., \& Berkoff, K. A. (1990). Psychometric characteristics of the Multidimensional Scale of Perceived Social Support. Journal of Personality Assessment, 55(3-4), 610-617. https://doi.org/ 10.1080/00223891.1990.9674095 